\title{
Assessment of the Various Sterilization Parameters in Ophthalmic Operating Rooms: A Microbiological Study
}

\author{
Harihar Deep Bhardwaj ${ }^{*}$, Praveen Kumar Prabhakar ${ }^{2}$ \\ ${ }^{1 *}$ Assistant professor, Department of Microbiology, \\ Rama Medical College Hospital \& Research Centre, Hapur, Uttar Pradesh, India. \\ ${ }^{2}$ Associate professor, Department of Microbiology, \\ Sakshi Medical College and Research Center, Guna District, Miana, Madhya Pradesh, India.
}

\begin{abstract}
Background: Hospital indoor air consists of a diverse and wide range of micro-organism. Since time the concept of sterilization of rooms was introduced by Lister, it has been a topic of worry regarding the sterilization of operation theatres. In view of this, we carried a microbiological surveillance of the overall efficiency of various disinfection methods of instrument sterilization in a health care centre where ophthalmic surgeries were carried out.
\end{abstract}

Materials \& Methods: The present study was carried out among patients that underwent various major and minor ophthalmic surgical procedures. In all the three operating room, sampling was conducted 184 times in each room. Before the starting of the next surgical procedure, sealing of the room was done before $12-14$ hours of the surgery. Weekly assessment of Environmental Bacteria Carrying Particle (BCP) load was done by sedimentation method prior to the commencement of the surgeries. In the surgical operating room, swabs were collected from the surfaces of the representative areas. Once in every two months, the evaluation of the contamination was done.

Results: In all the three operating room, sampling was conducted 184 times in each room. 8 sampling procedures in room 3 exhibited the highest bacterial count among the three rooms followed by 4 and 6 in room 1 and room 2 respectively. S. aureus was detected in 4 and 6 procedural cases in room 2

\section{INTRODUCTION}

A diverse and wide range of micro-organism is contained in the hospital indoor air. ${ }^{1}$ The sterilization of operation theatres is a topic of long term worry ever since the concept of aseptic room was put forward by Lister in 1866.2 Among the patients undergoing various surgical procedures in operation theatres, post-surgical infection and sepsis remains one of the leading causes of morbidity. ${ }^{3}$ Postoperative infections can be either of endogenous or exogenous origin. Factors associated with transmission of infective material exogenously in hospitals and clinics include presence of shedders of pathogenic microorganisms amongst the hospital personnel, use of inadequately sterilized equipment, contaminated environment and grossly contaminated surfaces. ${ }^{2}$ For minimizing the post-surgical consequences and for promoting the early wound healing, it is essential to maintain strict aseptic field and environment during and room 3. No S.aureus count was exhibited in operating room 1. Clostridium species were detected in 2 procedures each in room 2 and room 3 while room 1 showed absence of clostridium species. Non-significant results were obtained while comparing the room 1 and room 2, room 2 and room 3, and room 1 and room 3 for various environmental and surface sampling parameters.

Conclusion: There is high need for the routine microbiological surveillance of ophthalmic operating rooms to minimize the risk of development of post-surgical infections.

Key words: Micro-organism, Ophthalmic, Sterilization.

${ }^{*}$ Correspondence to:

Dr Harihar Deep Bhardwaj,

Assistant professor, Department of Microbiology,

Rama Medical College Hospital \& Research Centre, Hapur, Uttar Pradesh, India.

Article History:

Received: 25-06-2016, Revised: 15-07-2016, Accepted: 29-07-2016

\begin{tabular}{|l|c|}
\hline \multicolumn{2}{|c|}{ Access this article online } \\
\hline Website: & Quick Response code \\
www.ijmrp.com & \\
\hline DOI: & \\
10.21276/ijmrp.2016.2.4.041 & \\
\hline
\end{tabular}

surgical procedure. More than 50 percent of the additional day's spended by the patients in the hospital is added by the various hospital induced infections.

In comparison to UK and USA, India has higher incidence of postsurgical hospital induced infections. ${ }^{3,4}$ Strict asepsis is desired to be maintained in the ophthalmic operating room because of higher chances of risk of development of post-surgical infections including endophthalmitis. ${ }^{5}$ Especially in the ophthalmic camps, the incidence and frequency of occurrence of post-surgical endophthalmitis has increased. With following of proper protocols and sterilization procedure, incidence of such post-surgical eye infections can be greatly reduced. ${ }^{6}$ Hence; we carried a microbiological surveillance of the overall efficiency of various disinfection methods of instrument sterilization in a health care centre where ophthalmic surgeries were carried out. 


\section{MATERIALS \& METHODS}

The present study was carried out in the department of ophthalmology and department of microbiology, Rama Medical College Hospital \& Research Centre, Hapur, Uttar Pradesh, India and included all the patients that underwent various major and minor ophthalmic surgical procedures. The three operating rooms were named as Oper1, Oper 2 and Oper 3 for the present study. In all the three operating room, sampling was conducted 184 times in each room. Every weekend, high-level disinfection and sterilization procedure was carried out with formaldehyde with addition of small fraction of formalin at varying concentration. It was followed by additional fumigation followed by disinfection by ultra violet radiation before the staring of the surgical procedure. Before the starting of the next surgical procedure, sealing of the room was done before $12-14$ hours of the surgery. For neutralizing the irrigational effects of the formaldehyde solution, liquid ammonia was used two to three hours before the surgical procedure. Weekly assessment of Environmental Bacteria Carrying Particle (BCP) load was done by sedimentation method prior to the commencement of the surgeries. ${ }^{7}$ Standard bacteriological methods were used for the quantitative assessment of the colonies for running out the presence of staphylococcus aureus. Even if a single colony of $S$. aureus was detected, it was considered as a risk factor for the development of infection. In the surgical operating room, swabs were collected from the surfaces of the representative areas followed by their inoculation in Robertson's cooked meat media. Blood agar plates were further used for the inoculation of the anaerobic cultures after inoculation at thirty seven degree centigrade for four hours. Spore strips which were commercially available were used for the detection of efficacy of sterilization by autoclaves. In hospitals and health care centres, savlon diluted with water in 1:3 were used for the general disinfection of the rooms. For the detection of any contamination, the in-use sterilization bottles with the forceps were evaluated. Incubation of the plates made by taking samples from these bottles was done bat thirty seven degree centigrade for four hours followed by assessment of the colony growth. Once in every two months, the evaluation of the contamination was done. Data so obtained was analysed using Statistical Package for Social Science (SPSS) Version-16 data analysis software. Chi-square test was used for the analysis and a $p$-value of less than or equal to 0.05 was considered as statistically significant value.

\section{RESULTS}

Graph 1 highlights the environmental and surface sampling of the operating rooms. In all the three operating room, sampling was conducted 184 times in each room. 8 sampling procedures in room 3 exhibited the highest bacterial count among the three rooms followed by 4 and 6 in room 1 and room 2 respectively. S. aureus was detected in 4 and 6 procedural cases in room 2 and room 3. No S.aureus count was exhibited in operating room 1. Clostridium species were detected in 2 procedures each in room 2 and room 3 while room 1 showed absence of clostridium species. Table 1 shows the $p$-value for various environmental and surface sampling of operating rooms. Non-significant results were obtained while comparing the room 1 and room 2, room 2 and room 3, and room 1 and room 3 for various environmental and surface sampling parameters. Table 2 shows physical considerations for ventilation of operating room. Ideal range of relative humidity required was 30 to 60 percent. Ideal range of temperature which is desired is 20 to 23 degree centigrade. Table 3 shows the microbiological parameters and expected results.

Graph 1: Environmental and surface sampling of the operating rooms

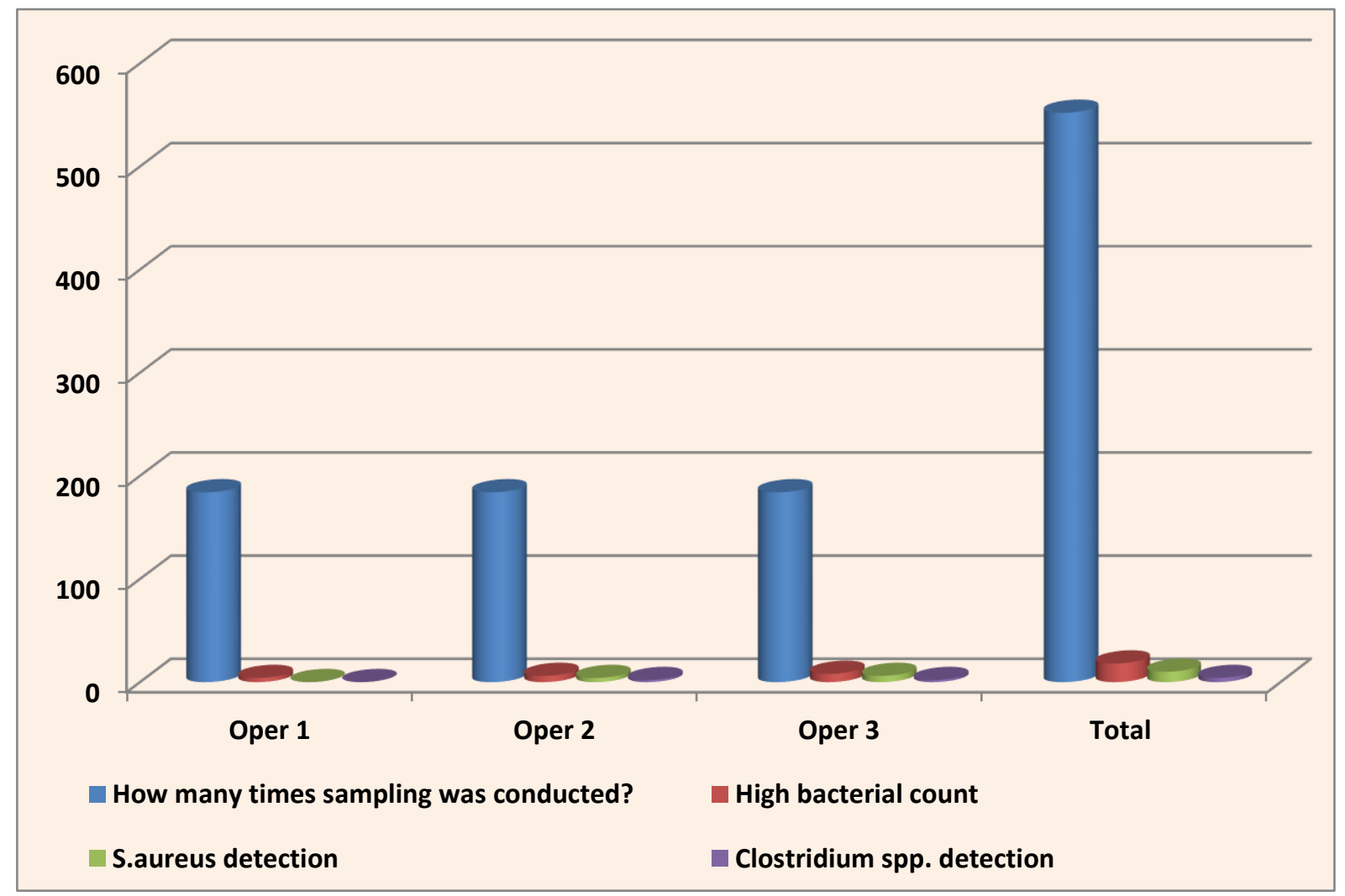


Harihar DB, Praveen K P. Assessment of the Various Sterilization Parameters in Ophthalmic Operating Rooms

Table 1: $p$-value for various environmental and surface sampling of operating rooms

\begin{tabular}{lccc}
\hline Parameter & Oper 1 Vs Oper 2 & Oper 2 Vs Oper 3 & Oper 1 Vs Oper 3 \\
\hline How many times sampling was conducted? & 0.61 & 0.61 & 0.61 \\
High bacterial count & 0.15 & 0.24 & 0.21 \\
S.aureus detection & 0.74 & 0.84 & 0.78 \\
Clostridium spp. detection & 0.53 & 0.64 & 0.52 \\
\hline
\end{tabular}

Table 2: Physical considerations for ventilation of operating room

\begin{tabular}{lc}
\hline Parameter & Ideal range \\
\hline Relative humidity & 30 to $60 \%$ \\
Temperature & 20 to 23 degree centigrade \\
Air changes & Minimum 15 total air changes per hour \\
Air movement & From clean to less clean areas \\
\hline
\end{tabular}

Table 3: Microbiological parameters and expected results

\begin{tabular}{|c|c|c|}
\hline Microbiology parameter & Proposed sampling frequency & Expected results \\
\hline $\begin{array}{l}\text { Use of biological indicators for } \\
\text { monitoring the sterilization processes }\end{array}$ & Monthly & No failure \\
\hline $\begin{array}{l}\text { - Monitoring of the OR environment for } \\
\text { BCP load }\end{array}$ & Weekly & $\begin{array}{l}\text { Bacterial load less than } 180 \text { per } \\
\text { cubic meter }\end{array}$ \\
\hline $\begin{array}{l}\text { - Assessment of the OR surfaces for the } \\
\text { presence of clostridium spores }\end{array}$ & $\begin{array}{l}\text { Utility not clear except for ensuring } \\
\text { cleanliness }\end{array}$ & $\begin{array}{l}\text { Clostridium spores should be } \\
\text { absent }\end{array}$ \\
\hline
\end{tabular}

\section{DISCUSSION}

Post-operative infections are directly affected by the layout of the operating room, instrument sterilization and sterilization protocol followed for disinfecting the operating rooms. The most critical evaluation is required for the checking of room and instrument sterilization procedures. It is an additional need and desire for the periodic and timely microbiological assessment of the working areas of the operating room in which surgery has to be performed. A positive relation has been observed in between the aerobic bacterial count and risk of development of infection. ${ }^{7}$ Hence; we carried a microbiological surveillance of the overall efficiency of various disinfection methods of instrument sterilization in a health care centre where ophthalmic surgeries were carried out.

In the present study, we observed a high Bacteria Carrying Particle (BCP) load along with presence of S.aureus in the operative room in approximately 5 percent of the occasions. No laminar air system was percent in the room of the health care centre. In the ophthalmic Operation theatres, it is advised to use the laminar air flow system although it is not documented properly by authorities. ${ }^{8,9}$ An efficiency of more than 90 percent has been observed while assessing then withdrawal of air passing through 5 $\mu \mathrm{m}$ filter. Byrns $\mathrm{G}$ et $\mathrm{a}^{10}$ compiled the data on sterilization of operating rooms and proposed that for the reduction in the microbial agents on the surfaces of the health care centres and the hospitals, fumigation has been required with the high concentrations of the toxic chemicals. In areas such as building decontamination has been effectively done by chemical fumigation even in cases after bioterrorism activities. Mass deaths and tissue damages occur in the areas which have been devoid of sterilization materials in such large scale instances. Full knowledge of side-effects and benefits along with advantages is necessary before expansile processes of various biological hazardous technologies should be expanded. They also reviewed the efficiency of fumigation method of inactivating the external surfaces of the environmental objects in reducing the infection rates of the patients. Dharan $S$ et $a^{11}$ reviewed the data on the complications post-operatively occurring in patients due to infections arising from surgical sites infections agents. It is still a topic of controversy that whether airborne bacteriological agents cause infectious processes in the health care workers and surgeons or not. Particles size of equal to or more than 5 micron is removed by the filtration system which is routinely employed by the modern surgical rooms. Kelkar $U$ et al ${ }^{12}$ analyzed the microbiological profiling of the ophthalmic operation theatre. They analyzed the environmental bacteriological profile, sterilization system and the failure processes of operating system over a period of 21 months. They also screened staphylococcus and beta-haemolytic streptococci among these infections. They observed that in more than 5 percent of the occasions, there was an associated significant increased risk of having airborne infections. From the results, they concluded in the operating rooms, there is a significant need for the standardization of sterilization protocols. Kelkar $U$ et al $^{13}$ in an another study assessed the contamination of patients in post-surgical phase by the fungal micro-organisms. From the results, they concluded that in the reduction of the fungal spores, quality and design of air conditioning unit plays an important role. Krogulski $A$ et al ${ }^{14}$ evaluated the effect of air conditioning system for reducing the microbial contamination of the operation theatre. From the results, they concluded that quality and effectiveness of the air 
conditioning unit effectively controls the contamination of the operation theatres from various biological agents. Friling $E$ et al ${ }^{15}$ analyzed the frequency and risk factors for the development of endophthalmitis in patients undergoing cataract surgery. From the results, they that fall in risk factors associated with decrease in incidence rate of endophthalmitis in Sweden has observed in the recent past time.

\section{CONCLUSION}

From the above observations, the present study conclude that there is a high need for the routine microbiological surveillance of ophthalmic operating rooms to minimize the risk of development of post-surgical infections. However, future standardizations are necessary for further exploration of the field.

\section{REFERENCES}

1. Patwardhan N, Kelkar U. Disinfection, sterilization and operation theater guidelines for dermatosurgical practitioners in India. Indian J Dermatol Venereol Leprol 2011;77:83-93.

2. Pitt D, Aubin J-M. Joseph Lister: father of modern surgery. Canadian Journal of Surgery 2012;55(5):E8-E9.

3. Ajaz M, Qadri GJ, Tabish SA, et al. Incidence of nosocomial infection in postoperative patients at a teaching hospital at Kashmir. JK Pract 2004;11:38-40.

4. Raymond DP, Pelletier SJ, Crabtree TD, Schulman AM, Pruett TL, Sawyer RG. Surgical infection and the aging population. Am Surg 2001;67(9):827-832.

5. Kaur N, Hans $\mathrm{C}$. Air bacterial isolations from operation theatres in a tertiary care hospital in India. J Clin Diagn Res 2007;1(2):8789.

6. Ram J, Kaushik S, Brar GS, Taneja N, Gupta A. Prevention of postoperative infections in Ophthalmic Surgery. Indian $\mathrm{J}$ Ophthalmol 2001;49:59-69.

7. World Health Organization. Hospital Acquired Infections: Guidelines to laboratory methods. Copenhagen: WHO Regional Publications European Series No.4. 1978. pp 2833

8. Forbes BA, Sahm DF, Weissfeld AS. Overview of conventional methods for bacterial identification. In: Bailey and Scott's Diagnostic Microbiology. 10th ed. St Louis: Mosby; 1998. pp. 167187.
9. White $A B$. Sterilization and disinfection in the laboratory. In: Collee JG, Fraser AG, Marmion BP, Simmons A, editors. Mackie and McCartney's Practical Medical Microbiology. 14th ed. New York: Churchill Livingstone; 1996. pp. 813-834.

10. Byrns G, Fuller TP. The risks and benefits of chemical fumigation in the health care environment. J Occup Environ Hyg 2011;8(2):104-12.

11. Dharan S, Pittet D. Environmental controls in operating theatres. J Hosp Infect 2002;51(2):79-84.

12. Kelkar U, Kelkar S, Bal AM, Kulkarni S, Kulkarni S. Microbiological evaluation of various parameters in ophthalmic operating rooms. The need to establish guidelines. Indian $\mathrm{J}$ Ophthalmol 2003;51(2):171-6.

13. Kelkar U, Bal AM, Kulkarni S. Fungal contamination of air conditioning units in operating theatres in India. J Hosp Infect. 2005 May;60(1):81-4.

14. Krogulski A, Szczotko M. Microbial air purity in hospitals. Operating theatres with air conditioning system. Rocz Panstw Zakl Hig 2010;61(4):425-9.

15. Friling $E$, Lundström M, Stenevi U, Montan P. Six-year incidence of endophthalmitis after cataract surgery: Swedish national study. J Cataract Refract Surg 2013;39(1):15-21.

\section{Source of Support: Nil.}

Conflict of Interest: None Declared.

Copyright: (c) the author(s) and publisher. IJMRP is an official publication of Ibn Sina Academy of Medieval Medicine \& Sciences, registered in 2001 under Indian Trusts Act, 1882.

This is an open access article distributed under the terms of the Creative Commons Attribution Non-commercial License, which permits unrestricted non-commercial use, distribution, and reproduction in any medium, provided the original work is properly cited.

Cite this article as: Harihar Deep Bhardwaj, Praveen Kumar Prabhakar. Assessment of the Various Sterilization Parameters in Ophthalmic Operating Rooms: A Microbiological Study. Int J Med Res Prof. 2016; 2(4):170-73. 